\title{
The development of speed-power qualities of schoolchildren with different typologies applying coordination training
}

\author{
Polevoy G.G. ${ }^{\mathrm{ABCDE}}$ \\ Vyatka State University, Kirov, Russia
}

Authors' Contribution: A - Study design; B - Data collection; C - Statistical analysis; D - Manuscript Preparation; E - Funds Collection.

\begin{tabular}{|c|c|}
\hline & \\
\hline Purpose: & $\begin{array}{l}\text { to determine the influence of coordination abilities on the development of speed-power qualities in 7-8 years } \\
\text { old schoolchildren with a different type of nervous system. }\end{array}$ \\
\hline Material: & $\begin{array}{l}\text { the pedagogical experiment was conducted in a regular school and lasted } 7 \text { months. The study involved } \\
\text { children } 7-8 \text { years old }(n=60) \text {. All schoolchildren were differentiated into } 3 \text { groups (in each group }-\mathrm{n}= \\
\text { 20). Coordination abilities were determined by the test " } 3 \times 10 \text { shuttle run". Speed- power qualities were } \\
\text { determined by the test "Standing Long Jump". The strength of the nervous system was diagnosed according } \\
\text { to the "Tapping test" method. }\end{array}$ \\
\hline Results: & $\begin{array}{l}\text { it was determined that it is necessary to develop the coordination abilities of } 7-8 \text { years old schoolchildren. It } \\
\text { was determined the interrelation of coordination abilities and speed-power qualities. It was confirmed the } \\
\text { effectiveness of a differentiated approach based on the typology of children. The results were realized at } \\
\text { physical education lessons at school. }\end{array}$ \\
\hline Conclusions: & $\begin{array}{l}\text { it is recommended to develop coordination abilities during } 12-15 \text { minutes in physical education classes } \\
\text { for schoolchildren. Such training will be more effective if consider the typology of the nervous system of } \\
\text { schoolchildren. }\end{array}$ \\
\hline
\end{tabular}

\section{Introduction}

Coordination abilities were classified about 70 years ago [1]. The level of their development affects the accuracy of different motor actions. The value of coordination in a person's life is huge. Such abilities allow you to solve unexpected motor problems accurately and quickly [2, 3]. The most common are general coordination abilities. They are the foundation for the development of special and specific abilities. A sensitive period for the development of coordination abilities is the primary school age [4].

The several studies devoted to interrelations of coordination abilities and physical qualities [5, 6]. Among the physical qualities should be noted speedpower qualities. Such qualities express in motor actions, which require significant muscle strength and quickness of motor actions [7].

The teachers often apply a differentiated approach to work with children. Such approach allows to reveal the internal reserves of the schoolchildren body, to reveal their physical and mental potential $[8,9]$. Despite differences in children, they can be grouped by criteria. For example, by age, gender, height, technical training [10.11]. One of these criteria is typology. In turn, typology features the express of the properties of the nervous system. The concept of the type of nervous system includes strength, mobility, lability, and some other features. The strength of the nervous system by activation process is a prospective study. The effectiveness of applying the differentiated approach using the criterion of the nervous system strength was proved in several studies [12, 13].

Other studies confirm:

This study highlights the potential relevance of using (c) Polevoy G.G., 2019

doi:10.15561/18189172.2019.0107 video feedback in fostering motor learning, motivation and self-assessment during a physical education program with young children [14];

Visual-motor integration is a complex ability that combines fine motor coordination (an aspect of school readiness) and visual-spatial reasoning skills [15];

Playing and exercising during the school day are important in fulfilling the recommendations for daily physical activity for children, as well as in promoting their mental and social health [16];

Results revealed that trait personality (particularly the social self-esteem aspect of extraversion) predicted lower anxiety and higher self-efficacy and intentions to exercise in both females and males [17].

We failed to find data concerning the influence of coordination abilities on the level of development of speed-power qualities of children 7-8 years old with different strength of the nervous system. This problem is the aim of this study.

Research hypothesis. If apply exercises for the development of motor actions coordination in children at physical education classes, the indicators of coordination abilities and indicators of speed-power qualities will improve. Such exercises are performed within 12-15 minutes. The load is regulated depending on the age of the children (7-8 years old) and the type of the nervous system.

\section{Material and methods}

Participants:

The pedagogical experiment involved 60 girls and boys of 7-8 years old who study in the first form of the ordinary school. Parents gave the written consent for the 
participation of their children in the experiment.

Design of research:

The children were healthy and admitted to physical education classes. Before the experiment, all schoolchildren were differentiated into 3 equal groups [18].

1) in the CG (control group) were children who trained according to the standard program of physical education for first-form pupils [19].

2) in the EG-1 (experimental group - 1) were schoolchildren who trained according to the standard program [19]. However, after a short warm-up, the children performed coordination exercises within 12-15 minutes. Exercises were easy to perform. Exercises without objects (running, jumping, somersaults) and with objects (hula hoop, stick, bench, ball). Coordination complexity in performing exercises increased due to the introduction of additional objects, new elements of exercises, changing the movement direction. And some other methodical techniques [7].

3 ) in the EG-2 (experimental group - 2) were schoolchildren who trained according to the standard program [19]. Children performed exercises on the development of coordination abilities [7]. The differentiated approach was applied at the classes with schoolchildren, which is based on the strength of the nervous system by the activation process. For children, the load was differentiated according to the strength of their nervous system. For schoolchildren with a strong nervous system, the load was intense, and for schoolchildren with a weak nervous system - the load was volume. The intensity of the load was increased by reducing the time of rest and increasing the number of exercises. The volume of the load was increased by increasing the number of exercise repetitions and increasing the time of rest $[13$, 20. 21].

In total, 59 training classes were conducted during the pedagogical experiment. Classes were held twice a week for 45 minutes.

At the beginning and at the end of the pedagogical experiment, all the children passed the development tests: coordination abilities ( $3 \times 10$ shuttle run); speed-strength qualities (standing long jump). In EG-2, children were differentiated into two subgroups of 10 people, according to the strength of the nervous system according to by activation process (tapping test).

Shuttle run [19]. Two lines are drawn at a distance of $10 \mathrm{~m}$. At the signal, children must run from start to finish (touch the line by hand). Then go back to the start line (touch it by hand) and cross the finish line.

The standing long jump with double beat [19]. Three attempts are provided. The best result is taken into consideration.

Tapping test [22]. The paper has six squares. At the signal, the students begin quickly put points inside one square within five seconds. Then move to another square. After the sixth square the exercise finishes. The number of points in each square sum up. A graph is constructed and the strength of the student's nervous system is determined.

Statistical analysis

Statistical processing of the results was carried out applying BioStat 2009 and Excel. The result was significant at $\mathrm{p}<0.05[23,24]$.

\section{Results}

Before the beginning of the pedagogical experiment, all schoolchildren passed the test for the development of coordination abilities. The children were differentiated into three identical groups ( $\mathrm{p}>0.05)$.

Schoolchildren in EG-2 were differentiated into two subgroups based on the strength of the nervous system by activation process. After the end of the pedagogical experiment, the following results were obtained (Table 1).

Table 1 revealed that the indicators of schoolchildren in all tests have changed.

Schoolchildren of the CG (trained according to the standard program) improved their results in the "standing long jump" test (by $3.2 \mathrm{~cm}$ ), but degraded results in the "shuttle run" test (from $10.3 \pm 0.6$ to $10.4 \pm 0.6$ ). Such indicators allow to confirm the low efficiency of application the standard teaching methods $(\mathrm{p}>0.05)$.

Schoolchildren of EG-1 (trained according to the standard program and performed exercises on the development of coordination abilities) improved their performance in both tests. The standing jump length increased by $10.6 \mathrm{~cm}(\mathrm{p}<0.05)$, and coordination abilities improved from $10.3 \pm 0.6$ to $10.1 \pm 0.5(\mathrm{p}>0.05)$. These results allow to confirm the effectiveness of the application of coordination training.

Schoolchildren of EG-2 significantly improved their

Table 1. Indicators of coordination and speed-power qualities of schoolchildren of 7-8 years old $(\mathrm{M} \pm \mathrm{m})$

\begin{tabular}{lllll}
\hline Indicators & Group & $\begin{array}{l}\text { Before the } \\
\text { experiment }\end{array}$ & After the experiment & $\mathbf{p}$ \\
\hline & CG & $10.3 \pm 0.6$ & $10.4 \pm 0.6$ & $>0.05$ \\
Shuttle run (s) & EG-1 & $10.3 \pm 0.6$ & $10.1 \pm 0.5$ & $>0.05$ \\
& EG-2 & $10.3 \pm 0.6$ & $9.7 \pm 0.5$ & $<0.05$ \\
Standin"g long jump (cm) & CG & $125.9 \pm 2.6$ & $129.1 \pm 3.1$ & $>0.05$ \\
& EG-1 & $131.3 \pm 3.4$ & $141.9 \pm 2.9$ & $<0.05$ \\
\hline
\end{tabular}


performance in both tests. In the $3 \times 10$ shuttle run test the results improved by $0.6 \mathrm{~s}(\mathrm{p}<0.05)$, and the standing long jump increased from $123.5 \pm 3.6$ to $144.5 \pm 4.1(\mathrm{p}<0.05)$. The obtained results confirm a high level of efficiency in the application of a differentiated approach to physical education classes. This approach is based on the strength of the nervous system by the activation process

\section{Discussion}

Coordination abilities are important for schoolchildren and athletes. These abilities allow to perform precise motor actions and save energy during several motor actions [2, $3,7]$. There are several classifications of coordination abilities [1]. These studies consider individual abilities and give general recommendations for improving motor actions performance. It is known that the primary school age is a favorable period for coordination development. Our research only confirms these studies.

Some studies point at the correlation between coordination abilities and physical qualities [5, 6, 25-27]. However, we didn't find studies devoted to the influence of coordination abilities on children's physical qualities (for example, on speed-power abilities). Such abilities are also very important in physical education, sports, daily life, and human activities. The results of our study confirm the existence of such an interrelation. Schoolchildren improved coordination indicators and increased speedpower indicators.

The differentiated approach is the basis of pedagogical work at school. Such an approach allows to reveal the inner potential of the group and each student $[8,9]$. Earlier we determined the wide variety of criteria that are applied to differentiate children into groups. One of these criteria is the typology of the nervous system $[12,13]$. It is evident the need for a clearer revealing the application of physical activity for children with different nervous systems.

The essence of the application of the typological criterion is to differentiate the load in children with different strengths of the nervous system. For schoolchildren with a strong nervous system, it is more efficient to apply an intense load, and for schoolchildren with a weak nervous system - a volume load [20.21].

It is important to understand that children with a weak nervous system by activation process are not weak in general. Such schoolchildren need a different physical activity. Children with a weak nervous system have several advantages over children with a strong nervous system. For example, they are able to perform longer monotonous actions. Such children have high reactivity and the ability to master complex coordination exercises. Schoolchildren with different types of the nervous system go to the same aim in different ways.

Thus, our study determined the interrelation of coordination abilities and speed-power qualities among schoolchildren of 7-8 years old. It was revealed the effective influence of coordination training on the indicators of speed-power qualities. It is determined the efficiency of applying a differentiated approach based on the typology of schoolchildren. This allows to confirm the achieving the aim and complete confirmation of the research hypothesis.

\section{Conclusion}

It is necessary to develop coordinating abilities of schoolchildren within 12-15 minutes at every physical education lesson. It is necessary to apply a differentiated approach, which is based on the typology of the nervous system of schoolchildren. This approach will significantly improve the indicators of coordination abilities and speedpower qualities.

The results of our research can be used by teachers, trainers, and athletes. The research is relevant and promising for the study of new interrelations of coordination abilities and various physical qualities.

\section{Conflict of interest}

The author declares that there is no conflict of interests.

\section{References}

1. Dveyrina OA. Coordination capacities: definition, classification, forms. Uchenye zapiski universiteta imeni P.F. Lesgafta. 2014;35:35-38. (in Russian).

2. Lyakh VI, Sadowski J, Witkowski Z. Development of Coordination Motor Abilities (CMA) in the System of Long-Term Preparation of Athletes. Polish Journal of Sport and Tourism. 2011;3:187- 197. https://doi.org/10.2478/v10197-011-0014-6

3. Jaakkola J, Watt A, Kalaja S. Differences in the Motor Coordination Abilities Among Adolescent Gymnasts, Swimmers, and Ice Hockey Players. Human Movement. 2017;1:44- 50. https://doi.org/10.1515/humo-2017-0006

4. Starosta W, Hirtz P. Sensitive and critical periods of motor co-ordination development and its relation to motor learning. Journal of human kinetics. 2002;7:19-28.

5. Sporiš1 G, Šiljeg K, Mrgan J, Kević G. Self-evaluation of motor and functional abilities among pupils. Croatian Journal of Education. 2011;13(2): 66-81.
6. Bozdoğan TK, Kızılet A. The effect of coordination and plyometric exercises on agility, jumping and endurance ability in badminton players. International journal of sports exercise \& training sciences. 2017;3(4):178- 187. https://doi.org/10.18826/useeabd.345236

7. Holodov ZhK, Khuznetsov VS. Theory and methodics of physical training and sports. Moscow: Akademia; 2009. (in Russian)

8. Solomatin VR. Individual approach in elaborating the manyyear training of young male swimmers. Uchenye zapiski universiteta imeni P.F. Lesgafta. 2010;61:103-107. (in Russian).

9. Santos S, Coutinho D, Gonçalves B, Schöllhorn W, Sampaio J, Leite N. Differential Learning as a Key Training Approach to Improve Creative and Tactical Behavior in Soccer. Research Quarterly for Exercise and Sport. 2018;89(1): 11- 24. https://doi.org/10.1080/02701367.2017.1412063

10.Khasawneh A. Prevailing Somatotypes and Their Contribution Rate to the Coordination Abilities among the Students of the Physical Education 
College. Physical Education. 2015;3:176- 187 https://doi.org/10.4236/ape.2015.53022

11.Fiorilli G, Mitrotasios M, Iuliano E, Calcagno G, Di Cagno A. Agility and change of direction in soccer: Differences according to the player ages. Journal of Sports Medicine and Physical Fitness. 2017;57(12):1597-1604.

12.Makarov YM, Hussain A-T. Typological profile of person properties of the basketball players aged 16-18 years old depending on the style of game activity. Uchenye zapiski universiteta imeni P.F. Lesgafta. 2011;73:122-4. (in Russian).

13.Drozdovski AK. The connection between typological complexes of properties of the nervous system, temperaments, and personality types in the professions and sports. Open access journal of sports medicine. 2015;6:72- 161. https://doi.org/10.2147/OAJSM.S75612

14.Shklyar BM. Usage of statistical methods in the pedagogical researches. Science Rise. 2015;5:39.

15.Lyakh VI, Zdanevich AA. Work program on physical culture, grade 1-4. Moscow: Education; 2010. (in Russian).
16.Polevoy G. The spatial orientation of the players with different type of nervous system. International Journal of Applied Exercise Physiology. 2017;6(4):1- 6. https://doi.org/10.22631/ijaep.v6i4.175

17.Polevoy G. The Development of the Ability to Equilibrium Football players 10-11 years with different Nervous System. Journal of Medical and Health Sciences. 2018;12(1):496499.

18.Raigorodskiy DJ. Practical psychodiagnostics. Methodics and tests. Samara: Bakhrakh-M; 2017. (in Russian).

19.Clark-CarterD.Effectsizeandstatisticalpowerinpsychological research. Irish Journal of Psychology, 2007;28:3- 12. https://doi.org/10.1080/03033910.2007.10446244

20.Kim TK. T test as a parametric statistic. Korean Journal of Anesthesiol. 2015;68(6):540- 546. https://doi.org/10.4097/kjae.2015.68.6.540

21.Jekauc D, Wagner MO, Herrmann C, Hegazy K, Woll A. Does Physical Self-Concept Mediate the Relationship between Motor Abilities and Physical Activity in Adolescents and Young Adults? PLOS ONE. 2017;12(1):1- 18. https://doi.org/10.1371/journal.pone.0168539

\section{Information about the author:}

Polevoy G. G.; (Corresponding author); http://orcid.org/0000-0002-3300-3908; g.g.polevoy@gmail.com; Vyatka State University; Moscow str., 36, Kirov, 610000, Russia.

Cite this article as:

Polevoy GG. The development of speed-power qualities of schoolchildren with different typologies applying coordination training. Pedagogics, psychology, medical-biological problems of physical training and sports, 2019;23(1):43-46. https://doi.org/10.15561/18189172.2019.0107

The electronic version of this article is the complete one and can be found online at: https://www.sportpedagogy.org.ua/index.php/PPS/issue/archive

This is an Open Access article distributed under the terms of the Creative Commons Attribution License, which permits unrestricted use, distribution, and reproduction in any medium, provided the original work is properly cited (http://creativecommons.org/licenses/by/4.0/deed.en).

Received: 10.01.2019

Accepted: 12.02.2019; Published: 27.02.2019 